\title{
Obturator Dislocation of the Hip: A Rare Sport Injury
}

\author{
Elyazid Houass", Elgaliou MR, Boufetal M, Bassir RA, Kharmaz M, Lamrani MO, Berrada MS
}

Departement of orthopedic surgery and trauma, ibn sina university hospital center Rabat Morocco Faculty of medecine and pharmacy-University Mohamed V Rabat Morocco

DOI: $10.36347 /$ sjams.2020.v08i11.037

| Received: 08.11.2020 | Accepted: 20.11.2020 | Published: 26.11.2020

*Corresponding author: Elyazid Houass

\section{Abstract}

Dislocation of the hip, in its obturator variety, is a rare entity, especially in sports practice, it requires reduction in less than 6 hours, performed by a qualified surgeon to avoid complications, we report the case of an obturator (anteroinferior) dislocation in a 19-years-old male practicing a sport of contact.

Keywords: Hip dislocation, obturator, closed reduction, osteonecrosis.

Copyright $(\mathcal{C}) 2020$ The Author(s): This is an open-access article distributed under the terms of the Creative Commons Attribution 4.0 International License (CC BY-NC 4.0) which permits unrestricted use, distribution, and reproduction in any medium for non-commercial use provided the original author and source are credited.

\section{INTRODUCTION}

Traumatic hip dislocation occurs when the ball-shaped head of the femur comes out of the cupshaped acetabulum of the pelvis, they are typically due to a high-energy trauma such a public road accident and more rarely during sport practice [1], it's a true emergency that requires immediate orthopedic evaluation and reduction.

\section{Patient and ObServation}

A 19-year-old patient, with no particular history, who has been practicing kick boxing and gets a hit while practicing. He immediately had a functional impotence of his left lower limb, fixed in flexion / abduction / external rotation of hip, and flexion of the knee.

Admitted to $\mathrm{H} 4$ in hospital, the clinical examination objectified the vicious attitude of his limb (figure 1), without associated vascular lesions.

A conventional pelvic $\mathrm{x}$-ray was taken and revealed the presence of an antero-inferior dislocation of the left hip (figure 2).

Emergency reduction under sedation was performed in using the following maneuvers: initial traction in the axis of the limb followed by flexion / internal rotation / abduction while maintaining traction.

A follow-up x-ray confirmed the reduction of dislocation and additional computed tomography ruled out the existence of associated lesions and/or intraarticular fragments (figure 4 and 5).
A four weeks discharge was prescribed under cover preventive anti-coagulation. The full weight bearing was allowed at eight weeks and practicing sport at 12 weeks.

Follow up for two years after the accident showed that the patient was pain free with full range of motion. There were no changes suggestive of avascular necrosis of the femoral head.

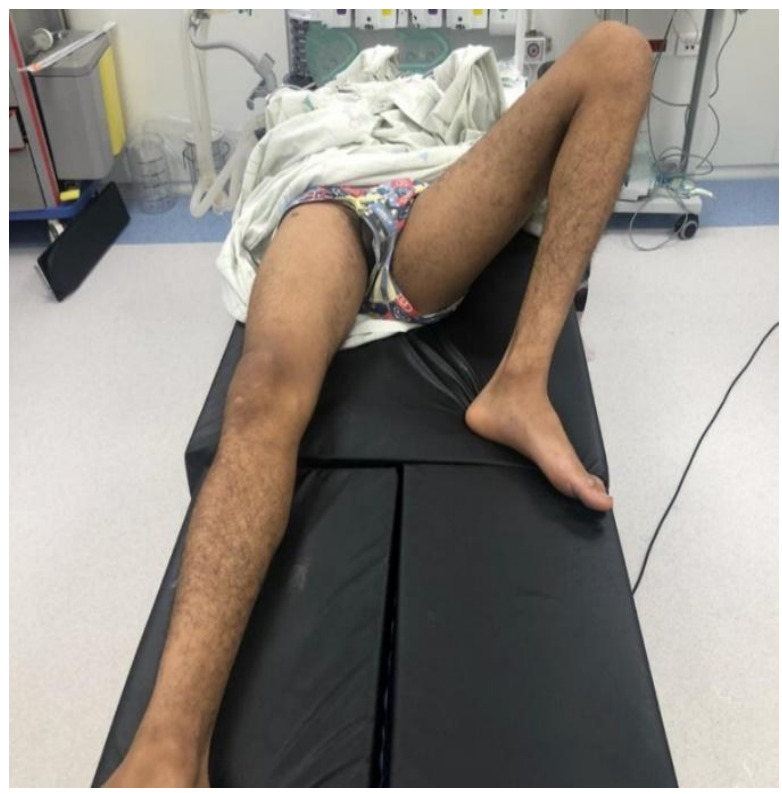

Fig-1: The vicious attitude of the limb fixed in flexion / abduction / external rotation of hip, and flexion of the knee 


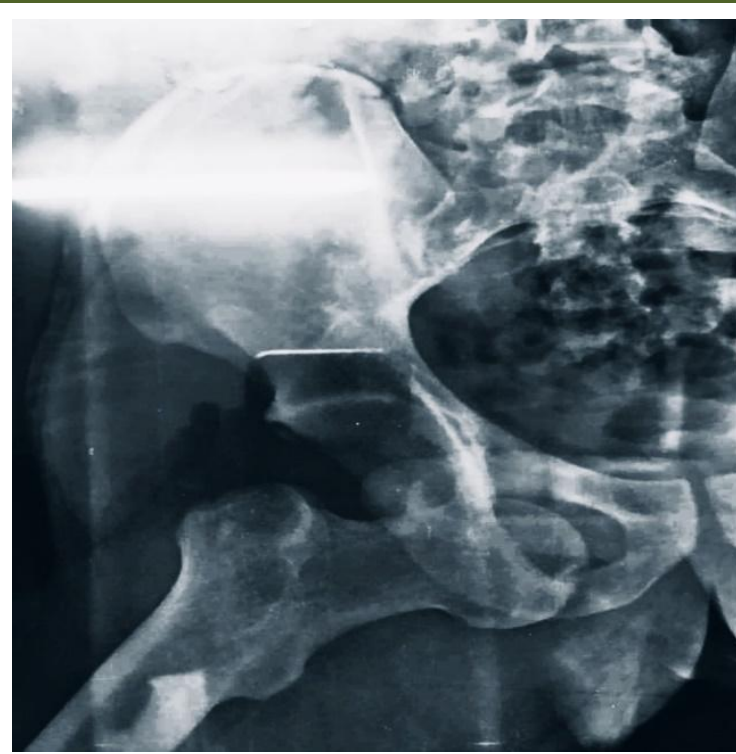

Fig-2: A conventional pelvic x-ray showing an obturator hip dislocation

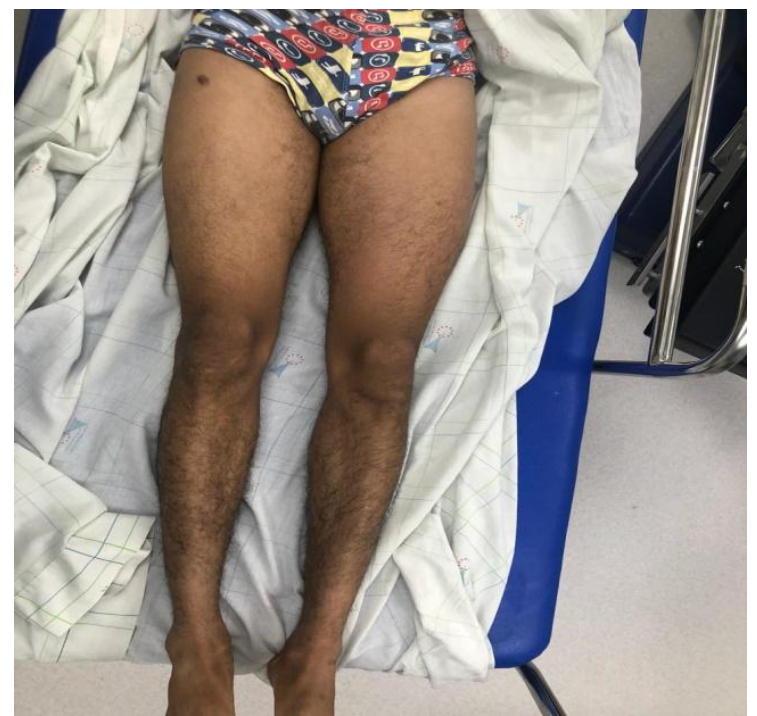

Fig-3: The attitude of the limb after reduction of the obturator hip dislocation

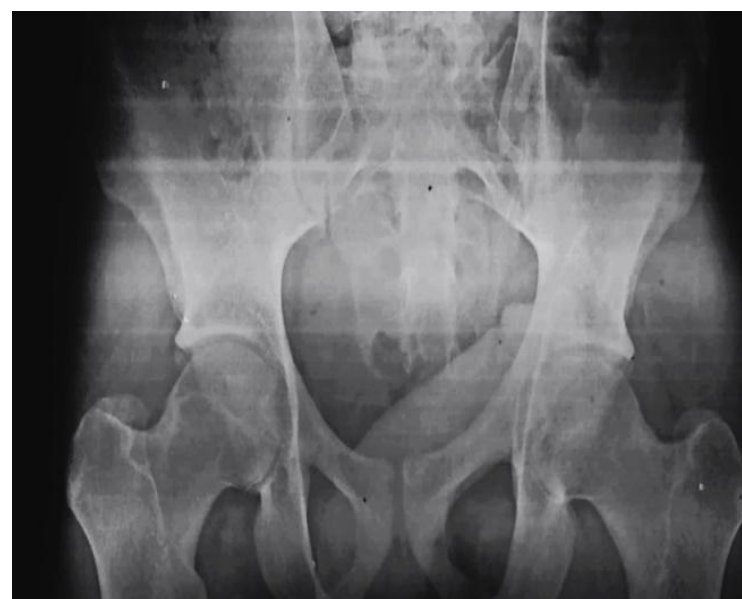

Fig-4: A conventional pelvic $x$-ray showing the reduction of the obturator hip dislocation

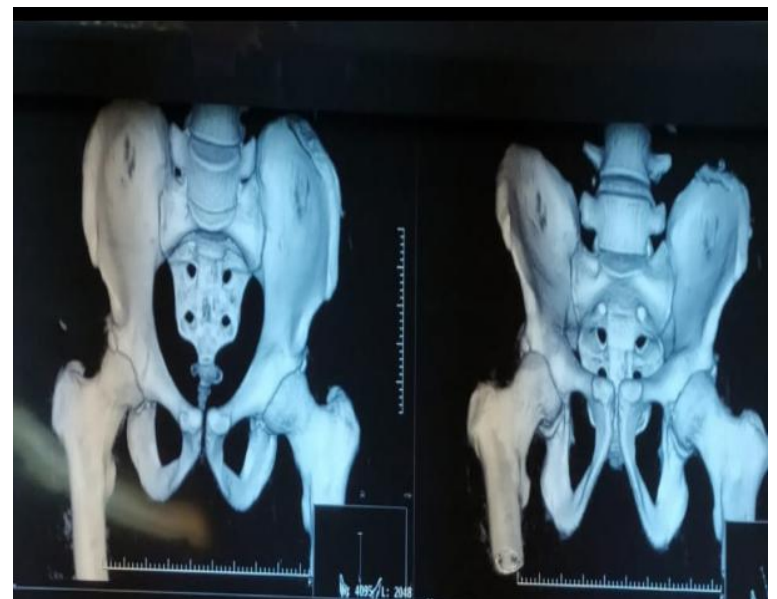

Fig-5: Computed tomography ruled out the existence of associated lesions and/or intra-articular fragments

\section{DISCUSSION}

Anterior hip dislocations are divided into two types according to the position of the femoral head: pubic or superior and obturator or inferior. The variety obturator is observed in 5 to $10 \%$ of cases [2].

The lower incidence of anterior dislocation may be due to in part to the strong anterior capsule and the Y-shaped ligament of Bigelow [2].

The mechanism reported for the occurrence of this type of dislocation involves a flexed hip in abduction and external rotation [3]. Road traffic accidents were responsible for the majority of anterior obturator dislocations of the hip with dashboard impact [4].

Associated lesions are not rare. Cartilaginous damage of the femoral head is frequent aaccording to an arthroscopic study after hip dislocation Ilizaliturri et al. [5]; these are posterior notches in anterior dislocations.

Capsular lesions can lead to irreducibility of the dislocation by phenomenon of incarceration [6]. Also, but exceptionally, the anterior dislocation may be responsible for nerve damage of obturator and femoral nerve [7].

The treatment of obturator dislocations is orthopedic. The reduction must be carried out urgently after a radiological assessment. This requires general anesthesia. There is no consensus about the reduction methods; Esptein [8] propose traction in the femur axis followed by progressive flexion of the hip in internal rotation and abduction, while maintaining traction.

In addition, some authors [9] report the need of a post-reduction traction of three weeks followed by discharge from 6 to 8 weeks, attitude aimed at reducing the risk of cephalic necrosis. However, there is no argument defending this practice. 
Catonné et al. [10] recommend early partial weight bearing then total weight bearing at day 15 with eviction of external rotation for three weeks. The outcome of an isolated hip dislocation is often favorable in 85 to $100 \%$ of cases according to the authors [11].

The essential complications are necrosis of the femoral head and coxarthrosis. The frequency of necrosis is $30 \%$ in adults [12]. But this figure mainly concerns dislocations associated with a fracture of the acetabulum or the femoral head; the rate of necrosis during isolated dislocations is probably lower [13]. The rate of avascular necrosis may be affected by the time the femoral head remains dislocated [14]. In our case, the reduction was made within 3hours, due to a diagnosis early and atraumatic reduction.

Posttraumatic coxarthrosis is a common longterm complication of dislocations and can happen even in the absence of necrosis [15]. With a follow-up of 15 months this complication did not occur in our patient.

\section{Conclusion}

Obturator dislocation of the hip in adults is rare. Its rarity is due to the inherent stability of the join, in this condition, early diagnosis and reduction under general anesthesia should be done to prevent further complications.

\section{REFERENCE}

1. Lima LC, Nascimento RA, Almeida VM, Façanha Filho FA. Epidemiology of traumatic hip dislocation in patients treated in Ceará, Brazil. Acta ortopedica brasileira. 2014;22(3):151-4.

2. Phillips AM, Konchwalla A. The pathologic features and mechanism of traumatic dislocation of the hip. Clin Orthop Relat Res. 2000 Aug;(377):710

3. DeLee JC. Fractures and dislocations of the hip. In: Rockwood CA Jr, Green DP, editors. Fractures in adults. 4thed. Vol. 2. Philadelphia: Lippincott Raven; 1996. 1756-803.

4. Sneath RJ, Morgan NP. Bilateral traumatic anterior dislocation of the hip joint. J Accid Emerg Me. 1997 Nov;14(6):391
5. Ilizaliturri Jr, VM, Gonzalez-Gutierrez B, Gonzalez-Ugalde H, and Camacho-Galindo J. Hip arthroscopy after traumatic hip dislocation. The American journal of sports medicine. 2011; 39(1_suppl), 50-57.

6. El Andaloussi Y, Essi FA, Arssi M, Cohen D, Trafeh M. Luxation traumatique de hanche irréductible par incarceration d'une capsule et du labrum entraînant un effet de boutonnière. Revue de chirurgie orthopédique et réparatrice de l'appareil moteur. 2006 May 1;92(3):279-82.

7. Cornwall R, Radomisli TE. Nerve injury in traumatic dislocation of the hip. Clinical Orthopaedics and Related Research®. 2000 Aug 1;377:84-91.

8. Epstein HC. Traumatic dislocations of the hip. Clinical Orthopaedics and Related Research (19762007). 1973 May 1;92:116-42.

9. Schlickewei W, Elsässer B, Mullaji AB, Kuner EH. Hip dislocation without fracture: traction or mobilization after reduction?. Injury. 1993 Jan 1;24(1):27-31.

10. Catonné Y, Meyer A, Sariali E, Biette G. Luxation de Hanche sans Fracture au Cours D'activités Sportives. InPathologie du complexe pelvi-fémoral du sportif 2009 Jan 1 (pp. 88-99). Elsevier Masson.

11. Dreinhofer KE, Schwarzkopf SR, Haas NP, Tscherne H. Isolated traumatic dislocation of the hip. Long-term results in 50 patients. The Journal of bone and joint surgery. British volume. 1994 Jan;76(1):6-12.

12. Glass A, Powell HD. Traumatic dislocation of the hip in children: an analysis of forty-seven patients. The Journal of Bone and Joint Surgery. British volume. 1961 Feb;43(1):29-37.

13. Tawari AA, Bahuva VD, Goregaonkar AB. A rare case of open anterior hip dislocation. Journal of Surgical Case Reports. 2013 Jan 1;2013(1):rjs035.

14. Upadhyay SS, Moulton A. The long-term results of traumatic posterior dislocation of the hip. The Journal of Bone and Joint Surgery. British volume. 1981 Nov;63(4):548-51.

15. Rodríguez-Merchán EC. Coxarthrosis after traumatic hip dislocation in the adult. Clinical Orthopaedics and Related Research®. 2000 Aug $1 ; 377: 92-8$ 